\title{
Influences of the Pandemic on the Assessment of Learning in Higher Education: The Case of ALGAN
}

\author{
Ana Júlia Viamonte \\ LEMA, DMA, Isep, P. Porto, Portugal.
}

\begin{abstract}
How to cite this paper: Ana Júlia Viamonte. (2021). Influences of the Pandemic on the Assessment of Learning in Higher Education: The Case of ALGAN. The Educational Review, USA, 5(5), 131-137. DOI: $10.26855 /$ er.2021.05.003
\end{abstract}

Received: March 31, 2021

Accepted: April 28, 2021

Published: May 20, 2021

Corresponding author: Ana Júlia Viamonte, LEMA, DMA, Isep, P. Porto, Portugal.

Email: ajv@isep.ipp.pt

\begin{abstract}
March 2020 will forever be known in the educational community as the month when almost all schools in the world closed their doors. Due to the pandemic, about $90 \%$ of students and all the world have been affected by the closure of schools. The speed of these closures and the rapid transition to "distance learning" allowed very little time to plan. The rush to move to online education has brought some associated risks, one of which is the assessment of learning. Teachers have not had time to plan and reflect on the necessary changes to be made to assessment with the passage to this type of teaching. In this work, we will start by reflecting on changes in the assessment of learning in higher education, especially those that were introduced during the pandemic. In a second point, the case of evaluation in a discipline of the 1st year and the 1st semester of an engineering degree will be presented. Finally, some opinions of the students involved in this process will be presented too.
\end{abstract}

Keywords

Assessment, Higher Education, Online Learning

\section{Introduction}

The assessment of learning in higher education has changed over time, not only due to the implementation of the Bologna Process but also due to the development of new assessment methods and lately due to the pandemic (PEREIRA, 2011). According to UNESCO, by the end of March 2020, 185 countries had closed schools, affecting $90 \%$ of the world's students. The speed of these closures and the rapid transition to "online learning" allowed very little time to plan or reflect on both the potential challenges and the potential opportunities (Callaghan, 2020). Covid-19 launched us all into a massive pedagogical experience, forcing the adoption and evaluation of new approaches like never before: Synchronous delivery (where students and teachers must be involved at the same time) versus asynchronous delivery (where they are not); social media versus traditional media; multimedia versus written work; home-based learning material versus commercial learning material (Callaghan, 2020).

Unlike the planned experiments in distance education in the pandemic context of Covid-19 improvised supply mode of school subjects for facilities Higher Education (IES), it has been designated as Remote Education Emergency (Hodges et al., 2020). Many HEIs have made adaptations for teaching using online resources in an unplanned way, disregarding important aspects of the reality of students and teachers, as well as pedagogical and technological aspects involved. One of the problems that teachers faced was the fact that certain powers are not subject to school online-as skills basic and social skills techniques. However, this change, required by the pandemic, may also be an appropriate 
time to change the very conception of education and activities resulting from it: a traditional education, focused on the teacher and the passage of contents for a student, centred student and his more active involvement in learning activities (Gusso, 2020).

The addition to this burst, the need arises for a different way to evaluate the effectiveness of learning. The pandemic of the new coronavirus (Sars-CoV2) has transformed the reality of the educational system, leading institutions of basic and higher education to adapt to distance learning. This highlighted a new challenge in addition to the way of teaching, the remote assessment of learning. Evaluation is indispensable in the teaching-learning process, this process measures the evolution of each student and proves (or not) the effectiveness of the teaching methodology adopted by the teacher. The classic models that quantify the student's knowledge based on mistakes and successes—and then approve or disapprove-had already been criticized even before the current scenario. With mass remote education, the opportunity arises to rethink old practices, to discover others that work for the virtual environment (Rabaello, 2020). In the context of higher education, evaluation gains a prominent role: the evaluation process cannot be limited to the verification of learning content, with the mere use of tests and works, because what is at stake is the professional training of the student. Here, the assessment should consider a broader perspective, since it involves the formation of a set of attitudes that are desired to be assumed by future professionals. For this reasoning, it is essential to provide students, through assessment, situations, and activities that enable the experience and the incorporation of attitudes in their training process (Borba et al., 2007).

In the current context, some questions arise (Bitencourt et al., 2013):

Evaluate in online learning is different from assessing in regular education?

How to reconcile traditional assessment methods within the scope of distance education?

What are the new trends in an assessment that arise with the current context of higher education?

The assessment as part of the construction process of knowledge is an inseparable practice of teaching and must - do not only $\mathrm{n}$ the end, but throughout the teaching-learning process. Thus, the assessment must be comprehensive, to enable the student to perceive his difficulties and recover. The traditional method of evaluation emphasizes knowledge with value, structured linearly and transmitted by the teacher to the student (Grillo, 2003). This one features—if to be done generally not the end of a semester, to define a note (Pellegrini, 2003). This method is also known as the informative method as it is not a merely informative activity to meet an institutional requirement and students undergo If the evidence to find the success or failure, definitively (Grillo, 2003). Many see traditional assessment, also known as summative, as an "opposition" to formative assessment (a method that is part of new trends in education), but the two are not opposed but have different purposes (Pellegrini, 2003). The main criticism of traditional assessment is that it is based on evidence, tests, called now is and chips without establishing intellectual links with students. Considering the dynamics of higher education and its objective operating conditions, it is necessary to observe the balance between the quantitative and qualitative levels, as there is no way to dispense with objective assessments (such as proof), nor be restricted to them. It is recommended that the teacher uses several practices that enable the established learning objectives and allow the teacher to communicate more effectively with his students about the progress of the learning process (Borba et al., 2007).

\section{The evaluation in ALGAN}

The main objective of this work is to reflect on the evaluation in higher education. We will be presented the assessment methods used in the course Linear Algebra and Analytical Geometry (ALGAN) of the 1st year and 1st semester of the degree in Electrical and Computer Engineering (LEEC), and the relationship between assessment and learning. Data from the last 10 years are presented and as we can see in Figure 1, this course has always had many students enrolled.

The evaluation in ALGAN has undergone several changes in the last 10 years (see Table 1 ).

Initially, in 2011/2012, the evaluation consisted only of a final exam, and then, over the years, other elements of the evaluation were introduced. As can be seen in Figure 2, as new assessment tools were introduced, there was a significant increase in the approval rate.

In the academic year 2020/2021, due to the pandemic and the restrictions imposed, part of the academic component and the assessment was online. All theoretical classes were online, and each practical class was divided into two shifts so that each week one shift had face-to-face classes and the other online. Thus, the students had face-to-face practical classes every 15 days and in the other weeks, the class was online. These constraints forced the assessment to change and, as we can see in Figure 2, there was a slight decrease in the approval rate. To try to understand if this reduction was 
due to the alteration of the assessment or the fact that part of the teaching component was online, a survey was given to students.

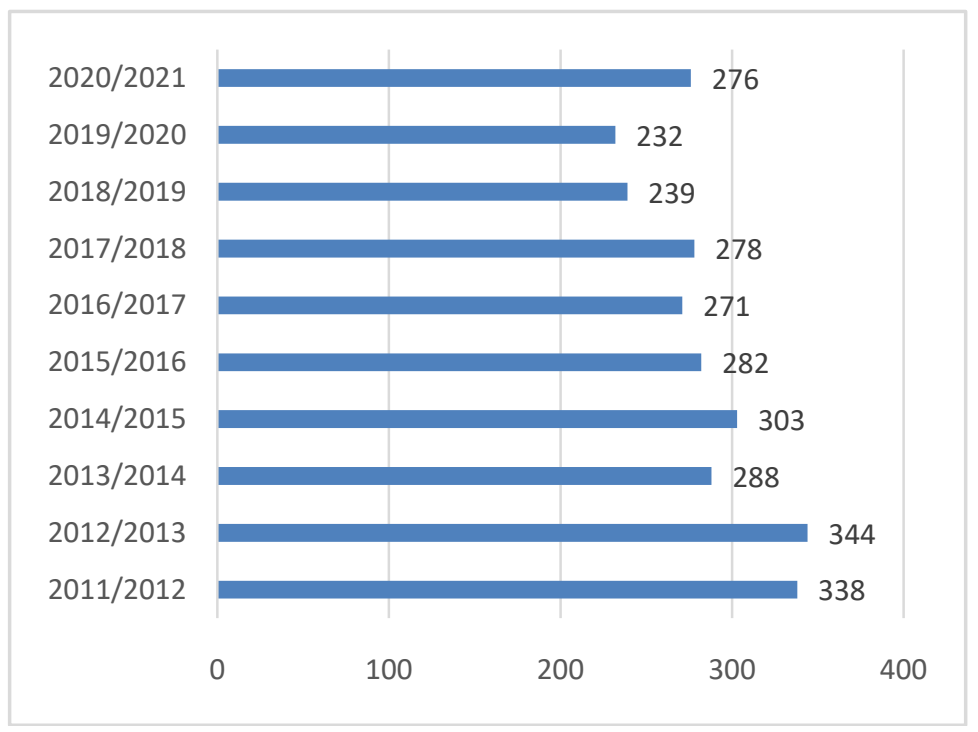

Figure 1. Number of students enrolled.

Table 1. Assessment ALGAN (the last 10 years)

\begin{tabular}{ll}
\hline School year & \\
\hline $2011 / 2012$ & Final exam \\
$2012 / 2013$ & 2 Frequencies, one in the middle of the semester and the other at the time of exams \\
$2013 / 2014$ & 2 Optional Tests and Tests in Moodle \\
$2014 / 2015$ & 2 Frequencies and 5 Tests in Moodle \\
$2015 / 2016$ & 2 Frequencies and Biweekly Tests in Moodle \\
$2016 / 2017$ & 2 Frequencies, Fortnightly Tests in Moodle, and Forums \\
$2017 / 2018$ & 2 Frequencies, Fortnightly Tests in Moodle, and Challenges \\
$2018 / 2019$ & 2 Frequencies, Tests in Moodle, and Game-Points system \\
$2019 / 2020$ & 2 Frequencies, Tests in Moodle, and Game-T Lessons and consultations \\
$2020 / 2021$ & ONLINE Classes - 2 Frequencies, Class Question (TP class) points (T classes) \\
\hline
\end{tabular}

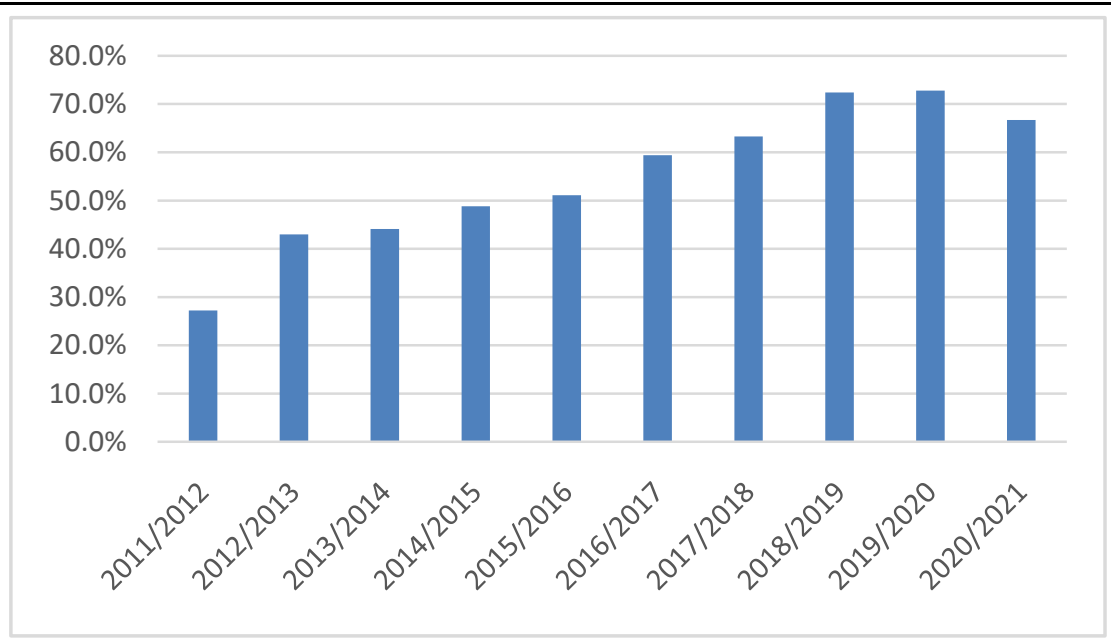

Figure 2. Approval rate. 


\section{The students' opinion}

The data were collected through an anonymous questionnaire survey, applied to all students of the 1st year of LEEC at ISEP. In total, $65 \%$ of enrolled students responded to the survey, that is, 179 students. Of these, as can be seen in Figure 3, the vast majority were new students in the discipline.

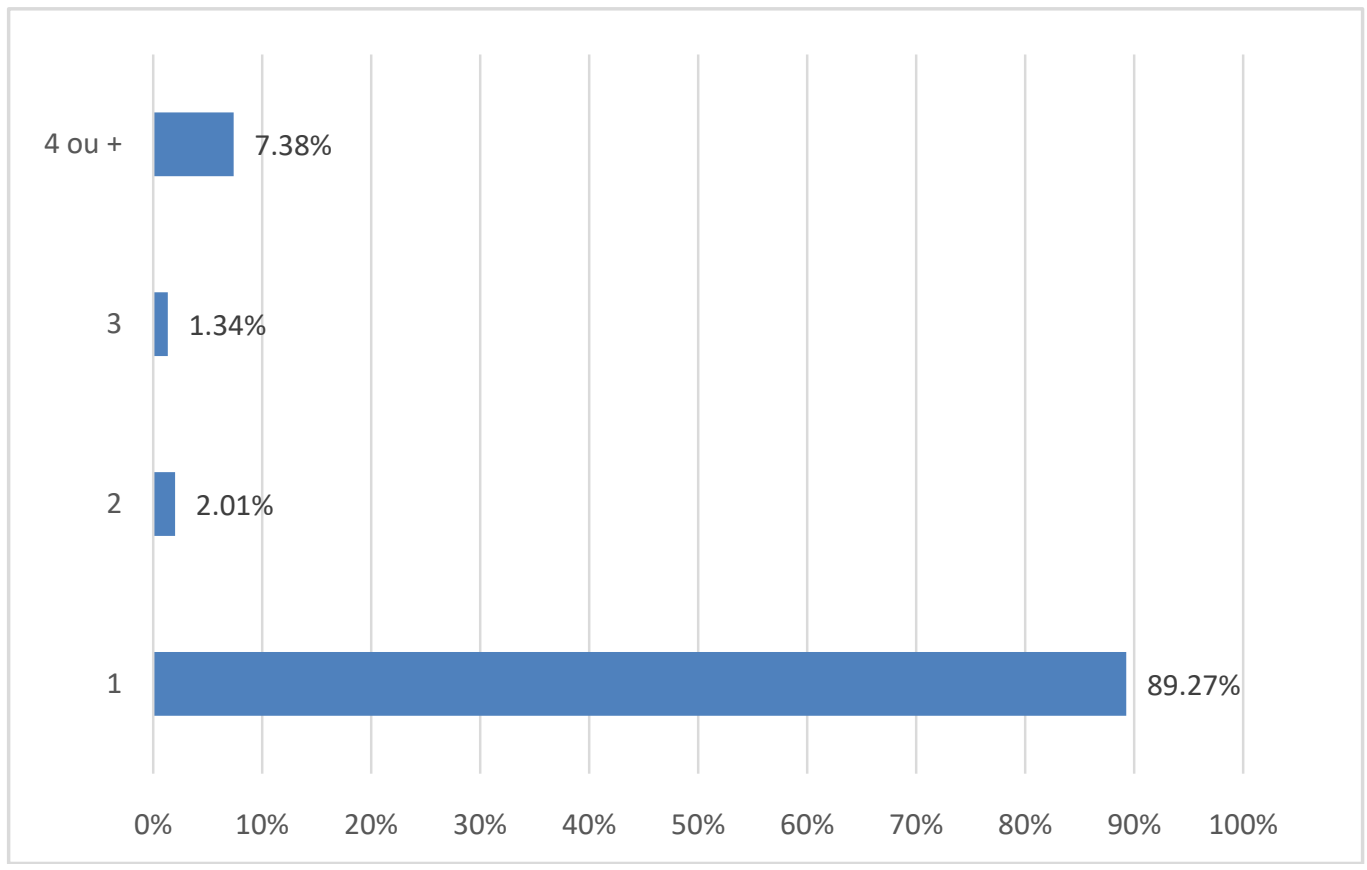

Figure 3. Number of registrations in ALGAN.

When asked about the functioning of the classes, that is, if despite the conditioning due to the pandemic, they thought that ALGAN's classes had gone well, most say yes, see Figure 4.

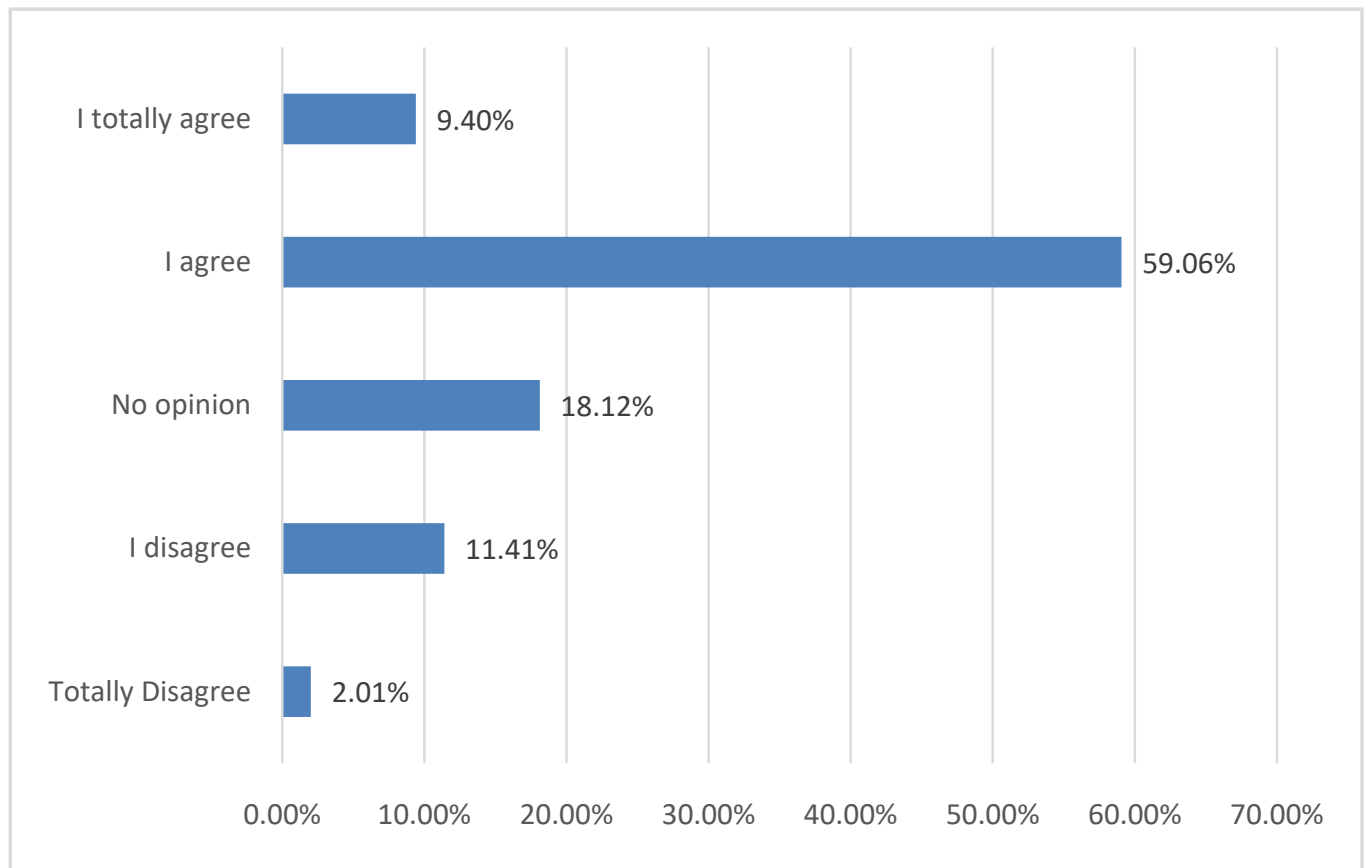

Figure 4. Answers to the question: Despite the constraints due to the pandemic, I think the ALGAN classes ran well. 
However, when asked if the fact that a large part of the classes had been online having affected motivation, opinions are very divided, see Figure 5.

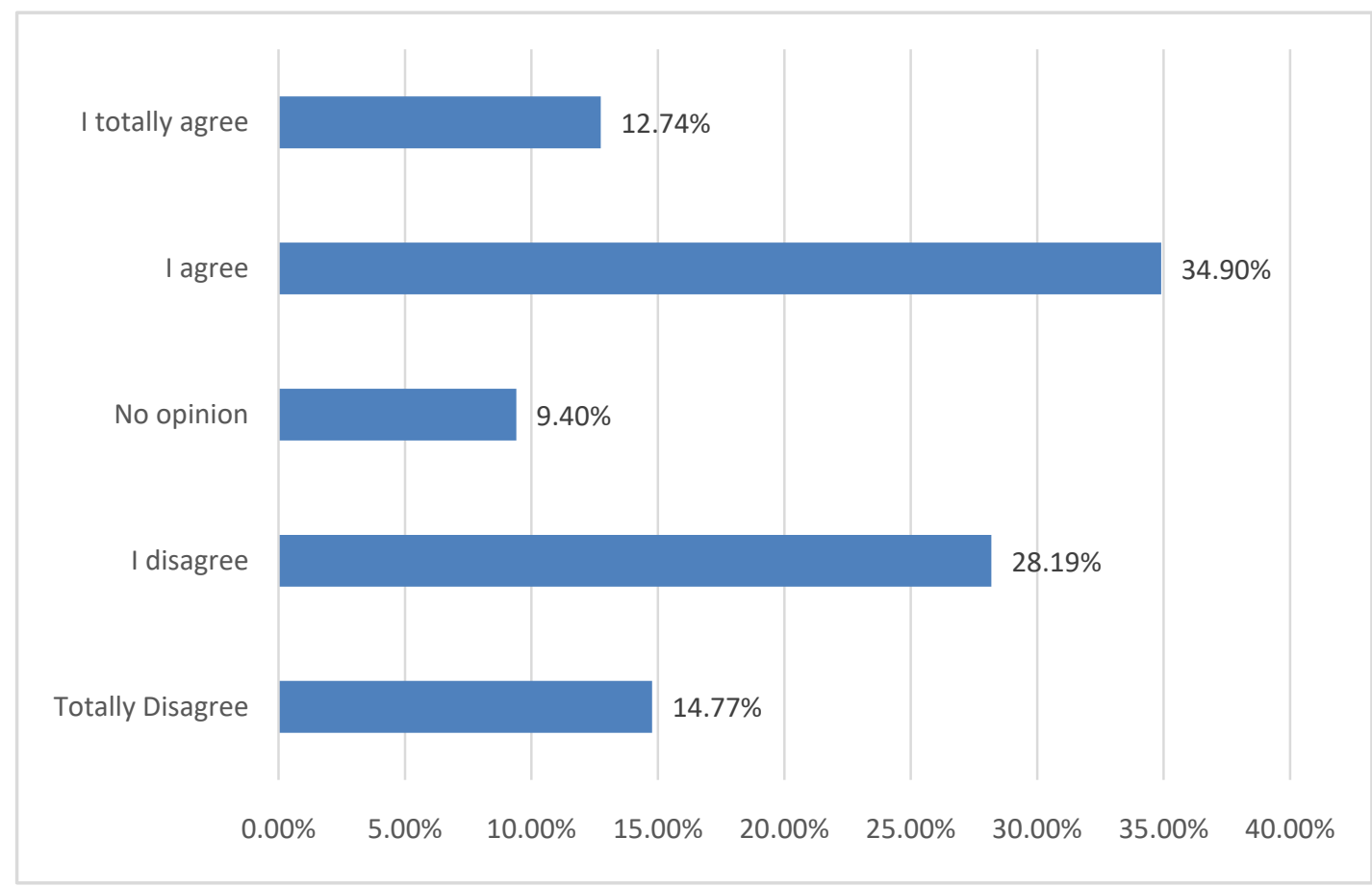

Figure 5. Answers to the question: Despite the distance, with several online classes, I felt motivated.

Although a large proportion of students have felt that the distance affects the motivation, the majority felt that the valuation method contributed to that if they could get involved in the course and to promote the learning, see Figure 6.

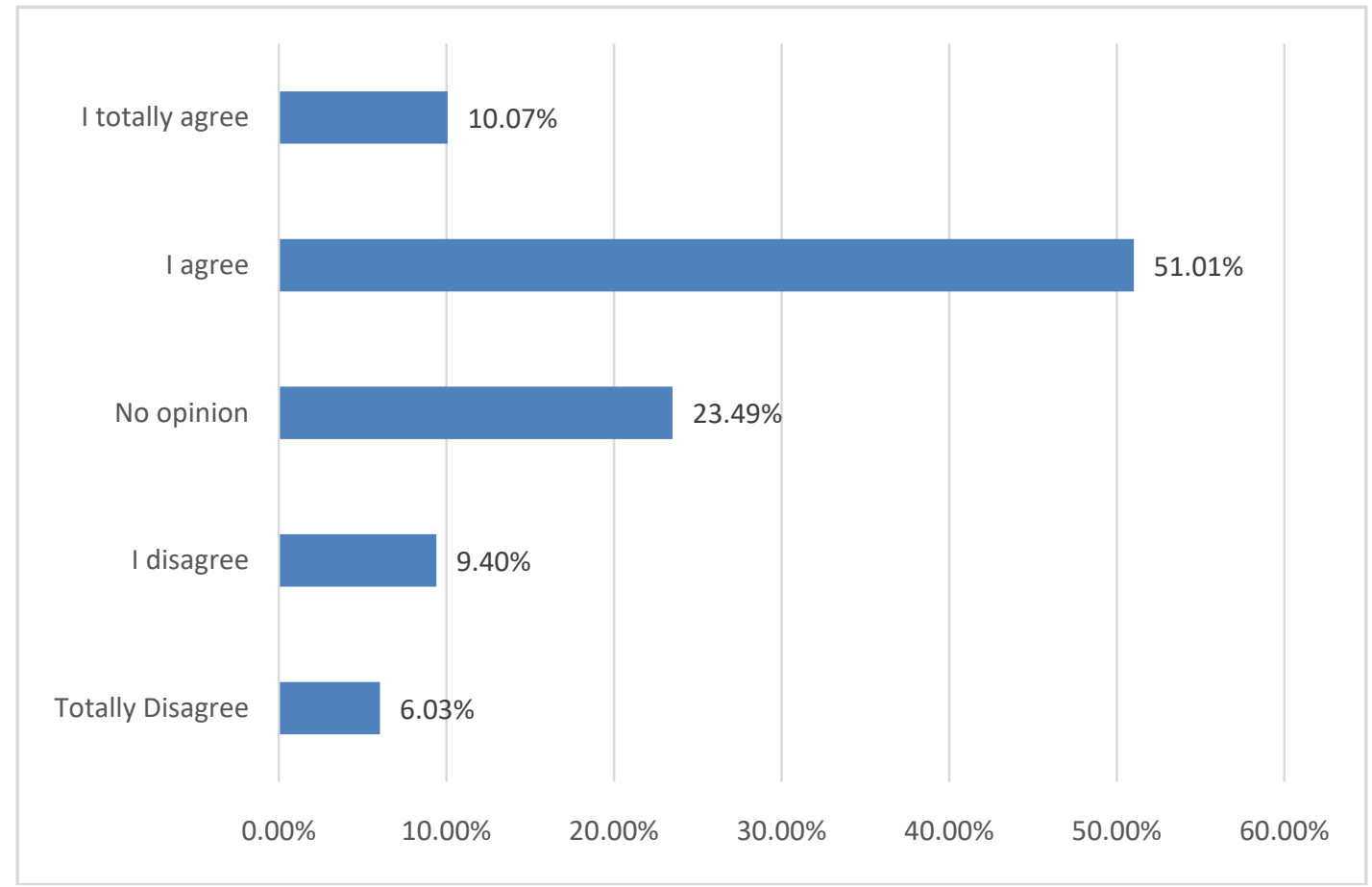

Figure 6. Answers to the question: The evaluation method helped me to get involved in the course and to promote my learning. 
When asked about the type of assessment they preferred, the vast majority opted for a mixed assessment, that is, assessment by frequency and by Moodle tests or class questions throughout the semester, see Figure 7.

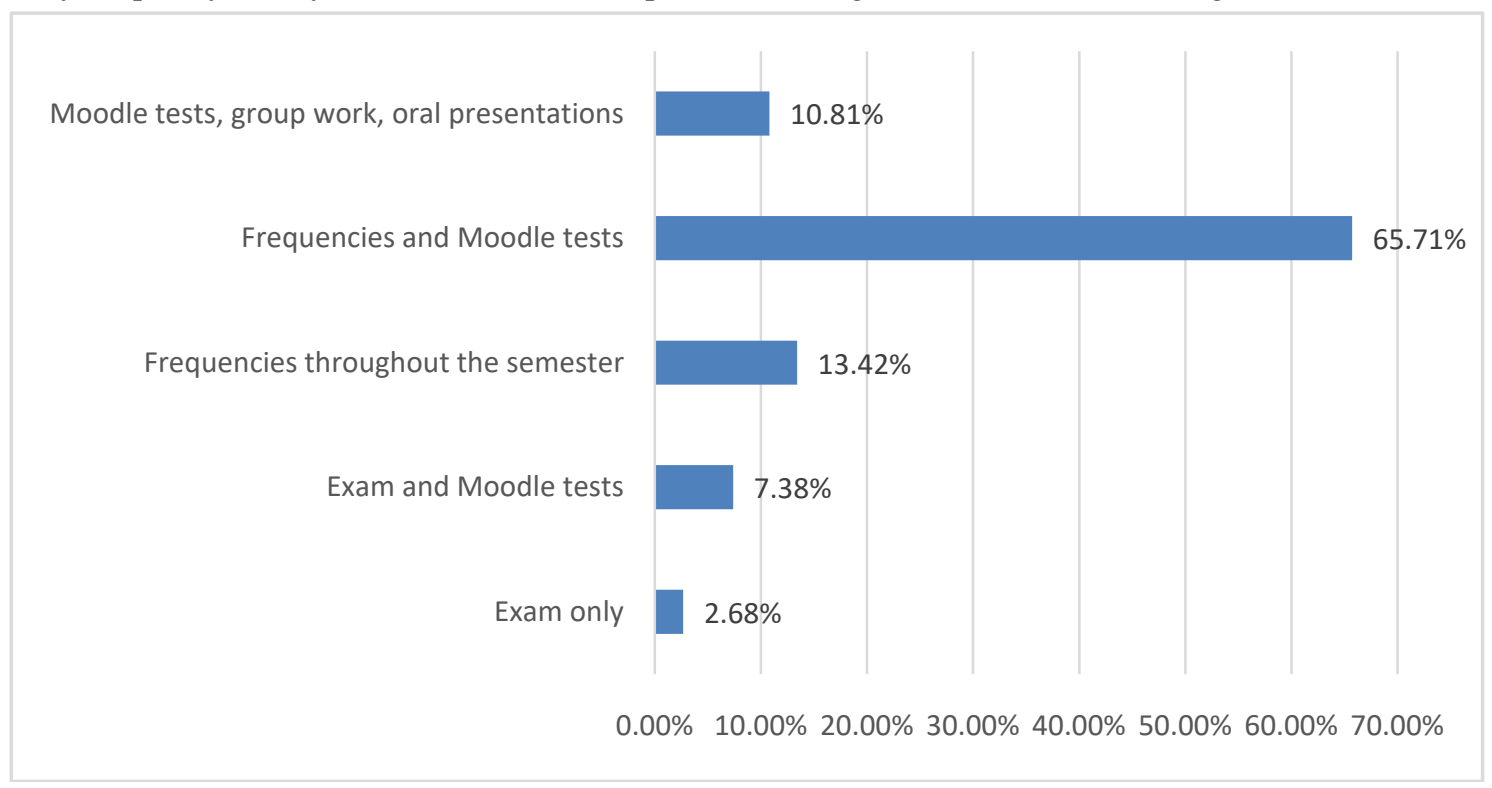

Figure 7. Answers to the question: What type of assessment would you prefer.

The data seem to reveal $r$ the aspects that students associate with more evaluation are learning and verification of knowledge. Regarding evaluation methods to most students state that prefer a combination of frequencies with alternative methods of assessment, or so-called new assessment methods, which allow the development of new knowledge and the development of their critical thinking.

\section{Conclusion}

In recent years, the assessment has undergone many changes and new evaluation methods refer to the importance of the elements of evaluation formative nature and essentially PROMPTED them to improve, regulate and guide the development of learning of the students. However, in Higher Education, assessment is still essentially summative. Therefore, it is possible to improve assessment and teaching practices in the context of higher education and, consequently, substantially improve what, and how, students learn (Fernandes, 2012). The assessment has a role determining in part by awareness of the students about what is really to learn and the effort they need to do to make it happen. Ways of assessing learning have undergone many changes, especially since the Bologna Process. Lately, with the pandemic and the consequent transition to online education, a new challenge has been posed in terms of how to assess learning.

This paper presents an experience of assessment in higher education, influenced by the pandemic and consequent shift to blended learning, online and face to part. In the evaluation of this curricular unit, formative and summative elements were considered. In the end, the students' opinions were heard through an anonymous questionnaire. The students, in general, agree that they feel more confident when classes are alive, especially the practical classes. They feel that the distance between the teacher and colleagues interferes with their motivation and learning. In any case, most students consider that the assessment is fairer when they mix frequencies with other elements of assessment throughout the semester to force them to follow the subjects and allow them to develop their critical spirit. Regarding the ALGAN discipline, the students considered that, although part of the teaching is online, they were able to get involved in the course, which was proven by the approval rate. Although slightly lower than that obtained in the previous year, it remained above $60 \%$.

As many researchers say, assessment methods and processes need to be further elaborated to lead to improvements in student learning. Evaluating online is not the same as evaluating in person. In online teaching we must adapt the assessment methods, however, it seems to us that a combination of summative and formative elements can help students to improve their learning. 


\section{References}

Bitencourt, B. M., Severo, M. B., and Gallon, S. (2013). Evaluation of Learning in Higher Education: Challenges and Potentialities in Distance Education. Electronic Journal of Education, 7(2), 211-226.

Borba, A. M., Ferri, C., and Hostins, R. C. L. (2007). Evaluation of Learning in Higher Education: Issues that emerge from teaching practice. Contrapontos Magazine, 7(1), 43-54.

Callaghan, R. O. (2020). Post-covid 19: will online be the future of education? In https://www.pbs.up.pt/pt/artigos-e-eventos/artigos/pos-covid-19-sera-o-online-o-futuro-da-educacao/, accessed on March 10, 2021.

Carvalho, C. and Pontes, A. S. (2020). Some reflections on the impact of the pandemic crisis on Higher Education. In https://aepq.tecnico.ulisboa.pt/files/sites/22/algumas-reflexoes-sobre-o-impacto-da-crise-pandemica-no-ensino-superior_vfinal .pdf, accessed on March 5, 2021.

Fernandes, D. and Fialho, N. (2012). Ten Years of Learning Assessment Practices in Higher Education: A Synthesis of Literature (2000-2009). In http://hdl.handle.net/10451/9000, accessed on March 5, 2021.

Grillo, M. C. (2003). Why talk about evaluation yet? In: GRILLO, Marlene; ENRICONE, Délcia (Orgs.). Evaluation: an open discussion. 2nd ed. Porto Alegre: EDIPUCRS, pp. 19-30.

Gusso, H. (2020). Higher Education in Pandemic Times: Guidelines for University Management. Inhttps://www.academia.edu/44242054/ENSINO_SUPERIOR_EM_TEMPOS_DE_PANDEMIA_DIRETRIZES_\%C3\%80_ GEST\%C3\%83O_UNIVERSIT\%C3\%81RIA, accessed on March 10, 2021.

Hodges, C., Moore, S., Lockee, B., Trust, T., and Bond, A. (2020). The Difference Between Emergency Remote Teaching and Online Learning. In https://er.educause.edu/articles/2020/3/the-difference-between-emergency-remote-teaching-andonline-learning, accessed on March 5, 2021.

Pellegrini, D. (2003). Evaluate to teach better. Nova Escola Magazine. Edition nº 159. São Paulo: Ed. Abril.

Pereira, D. A. R. (2011). Assessment of learning in higher education from the students' perspective. An exploratory study. In http://repositorium.sdum.uminho.pt/bitstream/1822/19122/1/Diana\%20Alexandra\% 20Ribeiro\%20Pereira.pdf, accessed on March 1, 2021. 